\title{
Cerebrovascular disease in childhood
} cancer survivors

\author{
A Children's Oncology Group Report
}

are

B. Morris, $\mathrm{MD}^{*}$

S. Partap, MD*

K. Yeom, MD

I.C. Gibbs, MD

P.G. Fisher, MD

A.A. King, $\mathrm{MD}, \mathrm{MPH}$

Address correspondence and reprint requests to Dr. E. Brannon Morris, 262 Danny Thomas Pl., MS 735, Memphis, TN 38105

brannon.morris@stjude.org

Editorial, page 1816

Supplemental data at www.neurology.org

\section{ABSTRACT}

Background: Curative therapy for childhood cancer has dramatically improved over past decades. Therapeutic radiation has been instrumental in this success. Unfortunately, irradiation is associated with untoward effects, including stroke and other cerebrovascular disease (CVD). The Children's Oncology Group (COG) has developed guidelines for screening survivors at risk for persistent or late sequelae of cancer therapy.

Objectives: This review summarizes the pathophysiology and relevant manifestations of radiationinduced CVD and outlines the specific patient groups at risk for early-onset stroke. The reader will be alerted to the availability of the COG recommendations for monitoring, and, when applicable, specific screening and treatment recommendations will be highlighted.

Methods: A multidisciplinary task force critically reviewed the existing literature and scored the evidence to establish the current COG guidelines for monitoring health of survivors treated with head and neck irradiation.

Results: Previous head and neck exposure to therapeutic radiation is associated with latent CVD and increased risk for stroke in some patient groups. Common manifestations of radiationinduced CVD includes steno-occlusive disease, moyamoya, aneurysm, mineralizing microangiopathy, vascular malformations, and strokelike migraines.

Conclusion: Risk for stroke is increased in survivors of pediatric CNS tumors, Hodgkin lymphoma, and acute lymphoblastic leukemia who received radiation to the brain and/or neck. As the population of survivors ages, vigilance for stroke and cerebrovascular disease needs to continue based on specific exposures during curative cancer therapy. Neurology ${ }^{\circledR}$ 2009;73:1906-1913

\section{GLOSSARY}

ALL = acute lymphoblastic leukemia; CCSS = Childhood Cancer Survivor Study; $\mathbf{C l}=$ confidence interval; $\mathbf{C O G}=$ Children's Oncology Group; CVD = cerebrovascular disease; NF1 = neurofibromatosis type I; RT = radiation therapy.

Childhood cancer survival rates have improved over the past several decades such that almost $80 \%$ of this population now survives beyond 5 years from diagnosis. ${ }^{1}$ Currently within the United States, there are an estimated 270,000 survivors of childhood cancer, including 1 in 640 adults between ages 20 and 39 years. ${ }^{2,3}$ Unfortunately, many of these survivors face significant medical hardship. Indeed, as evidenced by the Childhood Cancer Survivor Study (CCSS), a large multi-institutional cohort of long-term childhood cancer survivors diagnosed between 1970 and 1986, more than 60\% of the 10,397 adult participants have reported at least 1 chronic health condition, and almost 30\% have a severe or life-threatening condition at a relatively young mean age of 26.6 years. ${ }^{4}$

Chronic health conditions are often attributable to untoward effects of prior cancer therapy and may develop many years after initial treatment. As childhood cancer survivors age and transition from pediatric to adult care, medical providers will need to be familiar with the morbidities that commonly affect this population. To date, second malignant neoplasm (most notably, female breast

e-Pub ahead of print on October 7, 2009, at www.neurology.org.

*These authors contributed equally to this report.

From the Divisions of Neurology and Cancer Survivorship (B.M.), St. Jude Children's Research Hospital, Memphis, TN; Departments of Neurology (S.P., P.G.F.), Radiology (K.Y.), Radiation Oncology (I.C.G.), and Pediatrics (P.G.F.), Stanford University School of Medicine, CA; and Program of Occupational Therapy and Department of Pediatrics (A.A.K.), Washington University School of Medicine and St. Louis Children's Hospital, MO.

This study was supported by Children's Oncology Group Chairs' Grant U10-CA98543.

Disclosure: Author disclosures are provided at the end of the article. 


\begin{tabular}{|c|c|c|c|}
\hline \multirow[t]{3}{*}{ Table 1} & ular response to radiation & & \\
\hline & \multicolumn{3}{|l|}{ Artery size } \\
\hline & $\begin{array}{l}\text { Small arteries/ } \\
\text { arterioles }(<100 \mu \mathrm{m})\end{array}$ & $\begin{array}{l}\text { Medium arteries } \\
(100-500 \mu \mathrm{m})\end{array}$ & $\begin{array}{l}\text { Large arteries } \\
(>500 \mu \mathrm{m})\end{array}$ \\
\hline \multicolumn{4}{|l|}{ Time phase } \\
\hline $\begin{array}{l}\text { Acute/early } \\
\text { delayed }(<6 \mathrm{mo})\end{array}$ & $\begin{array}{l}\text { Detachment of endothelium from basement } \\
\text { membrane; increased BBB permeability through loss } \\
\text { of tight junction and/or increased } \\
\text { vesicular activity; cell pyknosis; cytoplasmic } \\
\text { vacuolation; nuclear swelling; perivascular edema; } \\
\text { acute oxidative stress response }\end{array}$ & & \\
\hline $\begin{array}{l}\text { Late delayed } \\
(>6 \mathrm{mo})\end{array}$ & $\begin{array}{l}\text { Progressive loss/abnormal proliferation of } \\
\text { endothelia; fibrinoid necrosis; adventitial fibrosis; } \\
\text { media hyalinization; intimal thickening; chronic } \\
\text { oxidative stress response; thrombus formation }\end{array}$ & $\begin{array}{l}\text { Intimal fibrosis; myointimal } \\
\text { formation; subintimal foam } \\
\text { cell plaque formation; } \\
\text { thrombosis }\end{array}$ & $\begin{array}{l}\text { Intimal fibrosis; } \\
\text { myointimal formation; } \\
\text { subintimal foam } \\
\text { cell plaque formation; } \\
\text { thrombosis }\end{array}$ \\
\hline Clinical sequelae & $\begin{array}{l}\text { Mineralizing microangiopathy; impaired } \\
\text { vasovasorum; possible brain necrosis }\end{array}$ & $\begin{array}{l}\text { Stenosis; aneurysm; } \\
\text { vascular malformation }\end{array}$ & $\begin{array}{l}\text { Stenosis; aneurysm; } \\
\text { vascular malformation }\end{array}$ \\
\hline
\end{tabular}

BBB $=$ blood-brain barrier

cancer), congestive heart failure, coronary artery disease, seizures, and stroke are recognized in childhood cancer survivors at a significantly higher than expected rate when compared with the general population. ${ }^{4-6}$

Although therapeutic radiation has played a prominent role in advancing the cure rate for many childhood cancers, damage to surrounding normal tissue may be profound. In adult cancer patients, prior irradiation is a recognized risk factor for the development of cerebrovascular disease (CVD). ${ }^{7}$ In younger patients exposed to radiation therapy (RT), the risk for developing CVD is less well described. The purpose of this review is to summarize the relevant pathophysiology and manifestations of radiation-induced CVD and to identify the specific patient groups at risk for early-onset stroke. In addition, the Children's Oncology Group (COG), a collaborative international cooperative clinical trials group, has compiled a series of longterm follow-up recommendations based on peer-reviewed literature for patients with a history of childhood cancer (http://www. survivorshipguidelines.org). ${ }^{8,9}$ The reader will be alerted to specific screening and treatment recommendations from these guidelines.

METHODS The methodology used for developing the COG guidelines with respect to literature review and scoring of evidence is provided as an appendix e-1 on the Neurology ${ }^{\circledR}$ Web site at www.neurology.org.
RESULTS Therapeutic radiation and the cerebral vasculature. In general, the biologic response of cerebral blood vessels to clinically relevant fractionated irradiation has not been well characterized. ${ }^{10,11}$ Presumed effects of RT on the human cerebrovasculature are generally extrapolated from in vitro or nonprimate, preclinical studies of systemic arteries that have received nonfractionated, supratherapeutic radiation. ${ }^{12,13}$ With this caveat in mind, the histologic and cellular responses of the human cerebrovasculature to RT may be characterized according to vessel diameter and time interval from treatment (table 1).

In this report, the microvasculature is considered, but our focus is on the delayed effects of RT in medium and large cerebral (including extracerebral internal carotid) arteries. Although initially "protected" from acute radiation toxicity by a relatively large muscular tunica media, the structural integrity of the endothelial monolayer in these larger vessels is also reduced over time. ${ }^{14}$ This delayed disruption is likely mediated by a chronic inflammatory or oxidative stress response. ${ }^{15}$ Continued disruption of the microcirculation that supplies larger blood vessels (vasa vasorum) may exacerbate this process. ${ }^{16}$ Ultimately, histopathologic changes reminiscent of advanced atherosclerosis such as intimal fibrosis and foam cell accumulation (reminiscent of advanced atherosclerosis) with resultant luminal narrowing and/or thrombus formation can ensue. Further weakening of the vessel wall can cause abnormal dilatation and tortuosity. ${ }^{14}$ Recognized clinical sequelae of these histopathologic changes, including vascular malformation, critical arterial stenosis/occlusion, stroke, moyamoya disease, and aneurysm are addressed below.

Cerebrovascular disease among childhood cancer survivors. Because individual cancer therapies vary, the COG Long-Term Follow-Up Guidelines are organized 
Table 2 Overview of irradiation in childhood cancer

\begin{tabular}{|c|c|c|c|c|c|}
\hline Tumor type & Treatment era & Typical RT dose & RT region of concern & CVD outcomes of concern & $\begin{array}{l}\text { COG recommendations } \\
\text { and consensus scoring }\end{array}$ \\
\hline $\begin{array}{l}\text { Head and neck } \\
\text { tumors (NPC, RMS } \\
\text { most common) }\end{array}$ & None specified & $40-60 \mathrm{~Gy}$ & Neck & See Hodgkin lymphoma & See Hodgkin lymphoma \\
\hline $\begin{array}{l}\text { Embryonal brain } \\
\text { tumors (including } \\
\text { medulloblastoma, } \\
\text { PNET) }\end{array}$ & None specified & 24-56 Gy & $\begin{array}{l}\text { Whole brain (with } \\
\text { additional "boost" to } \\
\text { primary tumor bed) }\end{array}$ & See ALL & See ALL \\
\hline Ependymoma & $\begin{array}{l}\text { 1960s-1970s } \\
1980 \text { s } \\
1990 \text { s-present }\end{array}$ & 45-60 Gy & $\begin{array}{l}\text { Focused to primary } \\
\text { tumor bed } \\
\text { Whole brain } \\
\text { CRT/IMRT }\end{array}$ & $\begin{array}{l}\text { Although CVD sequelae is } \\
\text { not well described with } \\
\text { more focused RT, depending } \\
\text { on tumor site and vessel } \\
\text { proximity, similar outcomes } \\
\text { to ALL are of concern }\end{array}$ & See ALL \\
\hline Craniopharyngioma & Contemporary & $50-55 \mathrm{~Gy}$ & Focal/CRT/IMRT & $\begin{array}{l}\text { See ependymoma; given } \\
\text { typical parasellar location, } \\
\text { increased exposure to circle } \\
\text { of Willis is presumed }\end{array}$ & See ependymoma \\
\hline $\begin{array}{l}\text { Astrocytoma and } \\
\text { other gliomas }\end{array}$ & None specified & 45-60 Gy & Focal/CRT/IMRT & See ependymoma & See ependymoma \\
\hline
\end{tabular}

$\mathrm{RT}=$ radiation therapy; CVD = cerebrovascular disease; COG = Children's Oncology Group; MR = magnetic resonance; IFRT = involved field radiation therapy; INRT = involved node radiation therapy; NPC = nasopharyngeal carcinoma; RMS = rhabdomyosarcoma; PNET = primitive neuroectodermal tumor; $\mathrm{CRT}=$ conformal radiation therapy; IMRT = intensity-modulated radiation therapy.

with respect to specific treatment exposure(s) rather than cancer type. Although these guidelines are quite helpful for medical providers who are managing the long-term complications in their patients, table 2 is provided as a reference to help neurologists identify which cancer survivors were likely exposed to radiation, the typical RT dose and location, outcomes of concern, and available screening recommendations.

Incidence of stroke in childhood cancer survivors. In general, published epidemiologic data pertaining to stroke in childhood cancer survivors is limited to the CCSS. The relative risk for stroke in this study cohort is almost 10-fold higher than its sibling control group. ${ }^{4}$
Patient groups of particular concern include adult survivors of childhood acute lymphoblastic leukemia (ALL), brain tumors, and Hodgkin lymphoma.

In leukemia survivors (mean age at time of study, 25 years [SD 12.9 years]), the rate of late-occurring stroke was 58.0 per 100,000 person-years $(95 \%$ confidence interval [CI] 41.2-78.7). Compared with their siblings, the relative risk of late-occurring stroke was 5.9 (CI 2.6-13.4).

The rate of late-occurring stroke in all brain tumor survivors (mean age at time of study, 25.8 years [SD 7.9 years]) was 267.6 per 100,000 person-years (CI 206.8-339.2). However, the rate of stroke was 
Figure 1 Occurrence of late-occurring stroke among brain tumor survivors

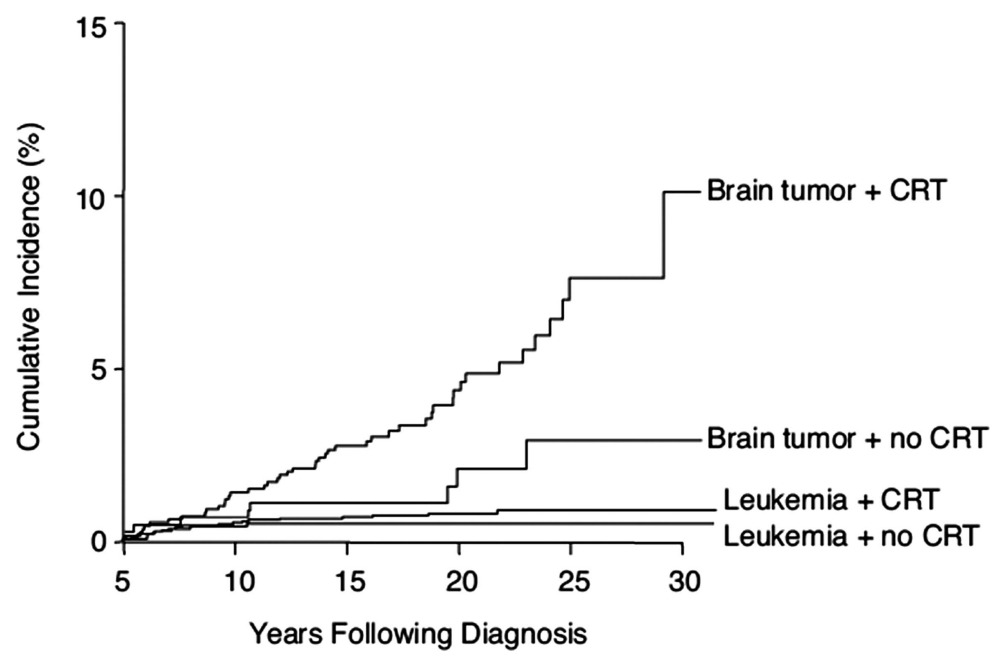

The occurrence of stroke over time among 5-year survivors of childhood leukemia with and without cranial radiation therapy (CRT; $\log -\operatorname{rank} p=0.32$ ) and brain tumors with and without CRT (log-rank $p=0.004)$. Reprinted with permission. (C) 2008 American Society of Clinical Oncology. All rights reserved. Bowers D, et al. J Clin Oncol 2006;24: 5277-5282.

significantly higher in those patients treated with radiation than those not treated with cranial radiation $(p=0.02 ; 339.5$ per 100,000 [CI 249.7-448.5]). Compared with siblings, the relative risk of lateoccurring stroke in brain tumor survivors previously treated with radiation was $37.2(\mathrm{CI}, 17.5-79.1)$. The cumulative incidence of stroke at 25 years from initial diagnosis was $6.9 \%$ (CI 4.47-9.33\%). An RT dose effect was suggested in both brain tumor and

\section{Figure 2 Incidence of late-occurring strokes with respect to radiation dose}

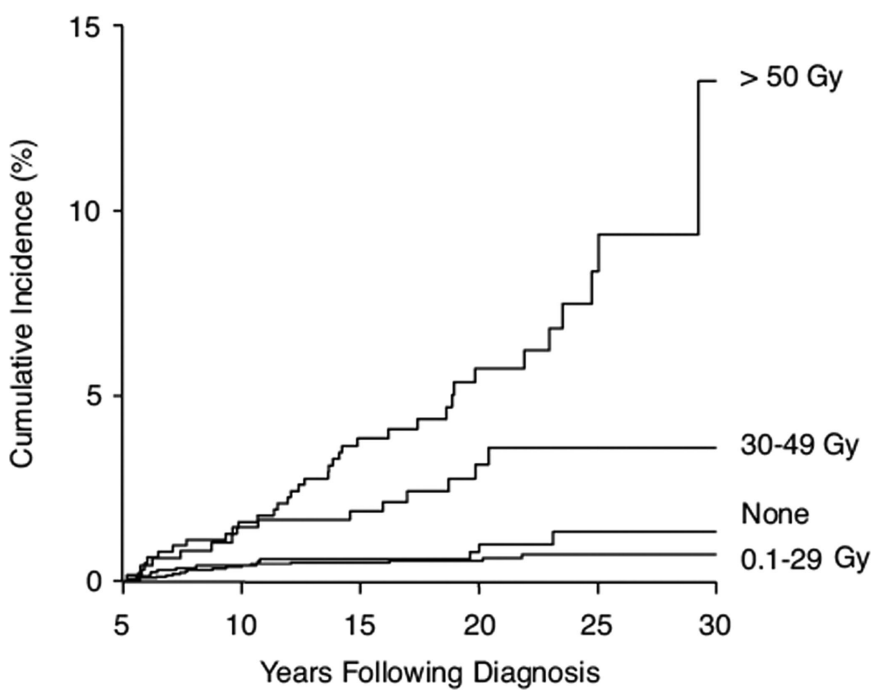

The occurrence of stroke over time by maximum dose of cranial radiation therapy to the temporal lobe, hypothalamus, and circle of Willis comparing no radiation vs 0.1 to 29 Gy ( $p=0.38$ ), 0.1 to 29 vs 30 to $49 \mathrm{~Gy}(p=0.001)$, and 30 to 49 vs $50 \mathrm{~Gy}(p=0.02)$. Reprinted with permission. (c) 2008 American Society of Clinical Oncology. All rights reserved. Bowers D, et al. J Clin Oncol 2006;24:5277-5282. leukemia survivors, because those exposed to cranial $\mathrm{RT} \geq 30$ Gy had an increased risk for stroke, with the highest risk among those treated with $\geq 50 \mathrm{~Gy}$ (figures 1 and 2). ${ }^{17}$

Adult survivors of childhood Hodgkin lymphoma treated with mantle RT (defined as radiation of major lymph nodes above the diaphragm from the inferior portion of the mandible to the insertion of the diaphragm) also seem at risk for stroke. Compared with their siblings, they had a 5.6-fold increased risk for stroke (CI 2.6-12.3) after adjusting for age at study, race, and gender. Given a mean age of 33.8 years (SD 7.1 years) at the time of study, the rate of late-occurring stroke was 109.8 per 100,000 personyears (CI 70.8-161.0). As opposed to direct effects of radiation on cranial vasculature, thromboembolic disease from either radiation-induced cardiovalvular dysfunction or premature arteriosclerosis may be causative. ${ }^{18-21}$

The reliance on a single study (the CCSS) to estimate risk and incidence of stroke in this patient population is of concern, and potential limitations should be considered. Although remarkable in breadth, the CCSS is a retrospective study that relied on self-report via questionnaire to ascertain risk and incidence of stroke. Validation of self-reported stroke was not possible, nor was it possible to determine type and location of stroke. In addition, the study did not ask about transient ischemic attacks. Finally, the sibling comparison group was older than both the leukemia and brain tumor survivors; thus, analyses for these groups were adjusted for age.

Potentially exacerbating host factors. The interaction of irradiation with specific host factors such as neurofibromatosis and the presence of an underlying cardiovascular risk profile can catalyze adverse outcomes. Patients with neurofibromatosis type I (NF1) have demonstrated an inherent susceptibility to cancer and vasculopathy. ${ }^{22-24}$ The NF1 locus, located on chromosome 17, regulates the function of neurofibromin, which is expressed in both endothelial and smooth muscle cells of blood vessels. ${ }^{25}$ The presence of NF1 alone increases the incidence of vasculopathy in noncancer patients, while radiation exposure further accelerates the potential for vascular injury. 26,27

Subsets of childhood cancer survivors are also at greater risk for obesity, ${ }^{28,29}$ insulin resistance, ${ }^{30}$ and suboptimal fitness levels. ${ }^{31}$ Most studies have focused on ALL, ${ }^{29}$ brain tumor ${ }^{32}$ and stem cell transplant survivors. ${ }^{33}$ Cranial radiation is associated with growth hormone deficiency, which likely contributes to obesity and lower high-density lipoprotein levels. ${ }^{34}$ These metabolic abnormalities may act synergistically with prior radiation vascular damage and 
further exacerbate development of cerebrovascular disease.

Radiation-induced cerebrovascular disease. Intracranial steno-occlusive disease (including moyamoya disease and mineralizing microangiopathy). Intracranial stenoocclusive disease after cranial irradiation in childhood was first reported more than 30 years ago. ${ }^{35}$ Since this initial documentation, similar reports (usually a single case or small case series) have been published that further substantiate this phenomenon (table e-1). In this selected review, the reported median latency period between RT and diagnosis of steno-occlusive disease is approximately 3 years, but the range is broad. The incidence of radiationinduced steno-occlusive disease is not well defined. However, patients with suprasellar and/or chiasmatic lesions, such as craniopharyngioma, optic gliomas (hypothalamic astrocytomas), and germ cell tumors, seem to be at highest risk for this complication because these tumors often require intense RT ( $\geq 45$ Gy) near the circle of Willis. ${ }^{36}$ Furthermore, cerebral hypoperfusion due to progressive occlusion of the internal carotid arteries with abnormal arterial collateral formation (moyamoya disease) is of particular concern in these patients. Children with NF1 treated for optic pathway gliomas seem to be at highest risk for moyamoya and, as compared with non-NF patients, may develop this vasculopathy earlier (median of 38 vs 55 months after radiation) as well as after lower radiation exposure (18-39 Gy). ${ }^{37,38}$ Although moyamoya (in the context of irradiation) seems to develop primarily within the pediatric age group, occlusive vasculopathy has been recognized in young adults decades after irradiation. Finally, mineralizing microangiopathy is a distinctive histopathologic process affecting small caliber vessels that leads to calcification of the basal ganglia. Its association with previous cranial irradiation is recognized and has been reported in doses as low as 15 Gy. ${ }^{39}$ In a large autopsy study of children with leukemia treated with cranial irradiation, mineralizing microangiopathy was detected in 28 of 163 patients (17\%) and as early as 10 months after completion of RT. ${ }^{40}$ The current COG Long-Term Follow-Up Guidelines (section 45) suggest an annual neurologic examination in patients with a history of $\geq 18$ Gy cranial irradiation (highest risk group in patients exposed to $\geq 50 \mathrm{~Gy}$ ). A brain MRI with diffusion-weighted imaging and magnetic resonance angiography is recommended as clinically indicated. No firm treatment recommendations are available because antiplatelet prophylaxis has not proved to be beneficial for moyamoya or postirradiation occlusive cerebral vasculopathy. Surgical revascularization for radiation-induced moyamoya may be of benefit, but, with the lack of developmental and functional outcome data, clinicians should be hesitant to believe that this procedure is standard care. ${ }^{41}$

Vascular malformation/aneurysm. Radiation-induced vascular malformations arise in children more often than adults and can assume many forms, such as venous-based cavernous malformations (cavernomas), telangiectasias of capillaries and veins, and aneurysms. Similar to postradiation steno-occlusive disease, information regarding these abnormalities has primarily been obtained by descriptive series and retrospective cohort analysis (table e-1). With regard to cavernomas, the largest series to date identified 10 of 297 pediatric brain tumor patients (3.4\%) who had developed a cavernoma at a median of 37 months after irradiation. ${ }^{42}$ Patients who receive $>30$ Gy may have a shorter latency for cavernoma development. ${ }^{43}$ Telangiectasias were found in $20 \%$ of leukemia and brain tumor survivors regardless of RT dose. ${ }^{44}$ Typically, cavernous malformations and telangiectasias are incidentally noted on follow-up neuroimaging, require no intervention, and pose limited risk. Occasionally, seizures, headache, and hemorrhage are associated with these lesions and may warrant surgical intervention. ${ }^{45}$ Radiation-induced intracranial aneurysms are believed to be a rare complication but are potentially life-threatening. ${ }^{46,47}$ The interval between RT and aneurysm detection is broadly reported. No correlation between radiation dose and time to aneurysm discovery has been elucidated. Diagnosis is often retrospective and occurs only after hemorrhage. Although no definitive recommendation can be provided regarding discovered unruptured aneurysms, treatment options are available. ${ }^{36}$ The current COG guidelines do not specifically address treatment-related vascular malformations or aneurysms. Nevertheless, because these abnormalities can hemorrhage and/or initiate seizures, the development of new neurologic findings in patients with previous cranial radiation exposure should necessitate neuroimaging.

Extracranial internal carotid stenosis. Irradiation to the head and neck is a well recognized risk factor for developing extracranial carotid stenosis. Adult patients previously treated with high-dose RT (40-70 Gy) for head and neck tumors are best described. ${ }^{48}$ Preexisting atherosclerosis at the time of treatment may be an exacerbating factor, and routine duplex ultrasound is often recommended. ${ }^{7,49-54}$ Of note, in the previously irradiated neck, carotid endarterectomy is often technically difficult because of fibrotic tissue and poor wound healing; carotid artery angioplasty/stent may represent a reasonable alternative intervention. ${ }^{55}$ In adolescents and young adults receiving neck irradiation, premorbid carotid atherosclerosis is presumably less common. Nevertheless, 
development of premature carotid stenosis is of concern in middle-aged cancer survivors who received neck irradiation at an early age. ${ }^{19,20,56}$ Imaging abnormalities have been observed in these patients at an increased rate compared with age-matched controls, but, overall, these changes tend to be mild in severity. Long-term follow-up will be required to determine whether the minor intima-media changes and early plaque formation predispose to premature stenosis. Current COG Long-Term Follow-Up Guidelines (section 66) recommend that survivors of childhood and young adult cancers who received $\geq 40 \mathrm{~Gy}$ to the neck region undergo yearly neurologic examination and assessment for diminished carotid pulses and the presence of carotid bruits. Diagnostic imaging of the carotid artery is recommended as clinically indicated. Consideration for baseline carotid duplex ultrasonography 10 years after RT should be given. To determine whether a formally prescribed screening program with diagnostic imaging is justified, future longitudinal studies are required.

Strokelike migraine after radiation therapy. Migraine variants have been reported in those treated with cranial irradiation several years after treatment. ${ }^{57} \mathrm{~Pa}$ tients may present with severe, recurrent headaches and prolonged but reversible neurologic deficits, mimicking complicated migraine or stroke. On testing, EEG demonstrates diffuse slowing over the affected cortex, whereas MRI may reveal a cortical ribbonlike enhancement with gadolinium administration. ${ }^{58,59}$ Pruitt et al. ${ }^{60}$ reported reversible dramatic gyral thickening with enhancement and hypermetabolism in symptomatic regions on MRI and $\left[{ }^{18} \mathrm{~F}\right]$ fluorodeoxyglucose PET imaging. Though the pathophysiology is unclear, radiation injury to the trigeminovascular system, ion channelopathies, and vasculopathy have been postulated. Common clinical features in these patients seem to be posterior tumor location, $\geq 50$ Gy cranial RT dose, latency greater than a year from irradiation, eventual recovery, and repeated episodes. ${ }^{59}$ Despite the unknown etiology, strokelike migraine attacks after RT are important to recognize to avoid needless interventions, such as angiograms, that can be costly and harmful.

No medication has been found to be completely effective, but conventional treatments with anticonvulsants used for migraine prophylaxis, such as carbamazepine and topiramate, and verapamil, propranolol, and warfarin have been helpful in some patients. ${ }^{58,59}$ Aspirin therapy and anticoagulation with warfarin as prophylaxis against potential cerebrovascular attacks have been used, despite a lack of evidence. As for all headache syndromes, lifestyle modification with regular exercise, avoidance of triggers, appropriate hydration and diet, and adequate sleep may improve outcome. The nonpharmacologic remedies of relaxation techniques and biofeedback may be beneficial but have not been studied in this population.

CONCLUSION The number of childhood cancer survivors entering adulthood is increasing. Although available literature is limited, the apparent potential for neurologic complications from previous oncologic treatment in this aging population necessitates increased awareness among adult neurology providers. With vigilant surveillance and monitoring, neurologists are well positioned to help prevent cerebrovascular accidents, to minimize unnecessary testing, and to improve the quality of life for this survivor population. To assist care providers, the COG has developed guidelines for screening survivors at risk for persistent or late sequelae of cancer therapy. To better inform future guidelines, larger prospective observational studies of select patient groups are warranted.

\section{ACKNOWLEDGMENT}

The authors thank Dr. Greg Albers for his critical review of this report.

\section{DISCLOSURE}

Dr. Morris, Dr. Partap, and Dr. Yeom report no disclosures. Dr. Gibbs serves on a clinical advisory board for and has received speaker honoraria from Accuray, Inc.; serves on the editorial board of Radiation Medicine Rounds; and has received research support from the Leach Foundation and the Cyberknife Society. Dr. Fisher serves/has served on editorial boards of the Journal of Pediatrics and the Journal of Clinical Oncology. Dr. King receives research support from the NIH [NHLBI K23HL079073 (PI)], HRSA [H46MC09231-01-00 (PI)], the Doris Duke Charitable Foundation, and the American Society of Hematology.

Received May 4, 2009. Accepted in final form August 20, 2009.

\section{REFERENCES}

1. Ries LAG, Harkins D, Krapcho M, et al. SEER Cancer Statistics Review, 1975-2003 [online]. Available at: http:// seer.cancer.gov/csr/1975_2003/. Accessed September 22, 2009.

2. Childhood Cancer Survivorship: Improving Care and Quality of Life. Washington, DC: National Academies Press; 2003.

3. Mariotto AB, Rowland JH, Yabroff KR, et al. Long-term survivors of childhood cancers in the United States. Cancer Epidemiol Biomarkers Prev 2009;18:1033-1040.

4. Oeffinger KC, Mertens AC, Sklar CA, et al. Chronic health conditions in adult survivors of childhood cancer. N Engl J Med 2006;355:1572-1582.

5. Bhatia S, Yasui Y, Robison LL, et al. High risk of subsequent neoplasms continues with extended follow-up of childhood Hodgkin's disease: report from the Late Effects Study Group. J Clin Oncol 2003;21:4386-4394.

6. Packer RJ, Gurney JG, Punyko JA, et al. Long-term neurologic and neurosensory sequelae in adult survivors of a childhood brain tumor: childhood cancer survivor study. J Clin Oncol 2003;21:3255-3261.

7. Smith GL, Smith BD, Buchholz TA, et al. Cerebrovascular disease risk in older head and neck cancer patients after radiotherapy. J Clin Oncol 2008;26:5119-5125. 
8. Children's Oncology Group. Long-Term Follow-Up Guidelines for Survivors of Childhood, Adolescent and Young Adult Cancers, Version 3.0. Arcadia, CA: Children's Oncology Group; 2008.

9. Landier W, Bhatia S, Eshelman DA, et al. Development of risk-based guidelines for pediatric cancer survivors: the Children's Oncology Group Long-Term Follow-Up Guidelines from the Children's Oncology Group Late Effects Committee and Nursing Discipline. J Clin Oncol 2004;22:4979-4990.

10. Brown WR, Thore CR, Moody DM, Robbins ME, Wheeler KT. Vascular damage after fractionated wholebrain irradiation in rats. Radiat Res 2005;164:662-668.

11. Yuan H, Gaber MW, Boyd K, Wilson CM, Kiani MF, Merchant TE. Effects of fractionated radiation on the brain vasculature in a murine model: blood-brain barrier permeability, astrocyte proliferation, and ultrastructural changes. Int J Radiat Oncol Biol Phys 2006;66:860-866.

12. Acker JC, Marks LB, Spencer DP, et al. Serial in vivo observations of cerebral vasculature after treatment with a large single fraction of radiation. Radiat Res 1998;149: 350-359.

13. Munter MW, Karger CP, Reith W, Schneider HM, Peschke P, Debus J. Delayed vascular injury after single high-dose irradiation in the rat brain: histologic immunohistochemical, and angiographic studies. Radiology 1999;212:475-482.

14. Fajardo LF. The pathology of ionizing radiation as defined by morphologic patterns. Acta Oncol 2005;44:13-22.

15. Chiang CS, Hong JH, Stalder A, Sun JR, Withers HR, McBride WH. Delayed molecular responses to brain irradiation. Int J Radiat Biol 1997;72:45-53.

16. Louis EL, McLoughlin MJ, Wortzman G. Chronic damage to medium and large arteries following irradiation. J Can Assoc Radiol 1974;25:94-104.

17. Bowers DC, Liu Y, Leisenring W, et al. Late-occurring stroke among long-term survivors of childhood leukemia and brain tumors: a report from the Childhood Cancer Survivor Study. J Clin Oncol 2006;24:5277-5282.

18. Bowers DC, McNeil DE, Liu Y, et al. Stroke as a late treatment effect of Hodgkin's Disease: a report from the Childhood Cancer Survivor Study. J Clin Oncol 2005;23: 6508-6515.

19. Hull MC, Morris CG, Pepine CJ, Mendenhall NP. Valvular dysfunction and carotid, subclavian, and coronary artery disease in survivors of Hodgkin lymphoma treated with radiation therapy. JAMA 2003;290:2831-2837.

20. King LJ, Hasnain SN, Webb JA, et al. Asymptomatic carotid arterial disease in young patients following neck radiation therapy for Hodgkin lymphoma. Radiology 1999; 213:167-172.

21. De Bruin ML, Dorresteijn LD, van't Veer MB, et al. Increased risk of stroke and transient ischemic attack in 5-year survivors of Hodgkin lymphoma. J Natl Cancer Inst 2009;101:928-937.

22. Rosser TL, Vezina G, Packer RJ. Cerebrovascular abnormalities in a population of children with neurofibromatosis type 1. Neurology 2005;64:553-555.

23. Beyer RA, Paden P, Sobel DF, Flynn FG. Moyamoya pattern of vascular occlusion after radiotherapy for glioma of the optic chiasm. Neurology 1986;36:1173-1178.

24. Hersh JH. Health supervision for children with neurofibromatosis. Pediatrics 2008;121:633-642.
25. Norton KK, Xu J, Gutmann DH. Expression of the neurofibromatosis I gene product, neurofibromin, in blood vessel endothelial cells and smooth muscle. Neurobiol Dis 1995;2:13-21.

26. Hilal SK, Solomon GE, Gold AP, Carter S. Primary cerebral arterial occlusive disease in children, II: neurocutaneous syndromes. Radiology 1971;99:87-94.

27. Ullrich NJ, Robertson R, Kinnamon DD, et al. Moyamoya following cranial irradiation for primary brain tumors in children. Neurology 2007;68:932-938.

28. Oeffinger KC, Mertens AC, Sklar CA, et al. Obesity in adult survivors of childhood acute lymphoblastic leukemia: a report from the Childhood Cancer Survivor Study. J Clin Oncol 2003;21:1359-1365.

29. Oeffinger KC, Buchanan GR, Eshelman DA, et al. Cardiovascular risk factors in young adult survivors of childhood acute lymphoblastic leukemia. J Pediatr Hematol Oncol 2001;23:424-430.

30. Gurney JG, Kadan-Lottick NS, Packer RJ, et al. Endocrine and cardiovascular late effects among adult survivors of childhood brain tumors: Childhood Cancer Survivor Study. Cancer 2003;97:663-673.

31. van Brussel M, Takken T, Lucia A, van der Net J, Helders PJ. Is physical fitness decreased in survivors of childhood leukemia? A systematic review. Leukemia 2005;19:13-17.

32. Heikens J, Ubbink MC, van der Pal HP, et al. Long term survivors of childhood brain cancer have an increased risk for cardiovascular disease. Cancer 2000;88:2116-2121.

33. Baker KS, Ness KK, Steinberger J, et al. Diabetes, hypertension, and cardiovascular events in survivors of hematopoietic cell transplantation: a report from the bone marrow transplantation survivor study. Blood 2007;109:1765-1772.

34. Talvensaari KK, Lanning M, Tapanainen P, Knip M. Long-term survivors of childhood cancer have an increased risk of manifesting the metabolic syndrome. J Clin Endocrinol Metab 1996;81:3051-3055.

35. Painter MJ, Chutorian AM, Hilal SK. Cerebrovasculopathy following irradiation in childhood. Neurology 1975; 25:189-194.

36. Keene DL, Johnston DL, Grimard L, Michaud J, Vassilyadi M, Ventureyra E. Vascular complications of cranial radiation. Childs Nerv Syst 2006;22:547-555.

37. Kestle JR, Hoffman HJ, Mock AR. Moyamoya phenomenon after radiation for optic glioma. J Neurosurg 1993;79: 32-35.

38. Kikuchi A, Maeda M, Hanada R, et al. Moyamoya syndrome following childhood acute lymphoblastic leukemia. Pediatr Blood Cancer 2007;48:268-272.

39. Shanley DJ. Mineralizing microangiopathy: CT and MRI. Neuroradiol 1995;37:331-333.

40. Price RA, Birdwell DA. The central nervous system in childhood leukemia, III: mineralizing microangiopathy and dystrophic calcification. Cancer 1978;42:717-728.

41. Fung LW, Thompson D, Ganesan V. Revascularisation surgery for paediatric moyamoya: a review of the literature. Childs Nerv Syst 2005;21:358-364.

42. Burn S, Gunny R, Phipps K, Gaze M, Hayward R. Incidence of cavernoma development in children after radiotherapy for brain tumors. J Neurosurg 2007;106:379-383.

43. Heckl S, Aschoff A, Kunze S. Radiation-induced cavernous hemangiomas of the brain: a late effect predominantly in children. Cancer 2002;94:3285-3291.

44. Koike S, Aida N, Hata M, Fujita K, Ozawa Y, Inoue T. Asymptomatic radiation-induced telangiectasia in children 
after cranial irradiation: frequency, latency, and dose relation. Radiology 2004;230:93-99.

45. Xia C, Zhang R, Mao Y, Zhou L. Pediatric cavernous malformation in the central nervous system: report of 66 cases. Pediatr Neurosurg 2009;45:105-113.

46. Sciubba DM, Gallia GL, Recinos P, Garonzik IM, Clatterbuck RE. Intracranial aneurysm following radiation therapy during childhood for a brain tumor: case report and review of the literature. J Neurosurg 2006;105:134-139.

47. Jensen FK, Wagner A. Intracranial aneurysm following radiation therapy for medulloblastoma: a case report and review of the literature. Acta Radiol 1997;38:37-42.

48. Murros KE, Toole JF. The effect of radiation on carotid arteries: a review article. Arch Neurol 1989;46:449-455.

49. Cheng SW, Ting AC, Lam LK, Wei WI. Carotid stenosis after radiotherapy for nasopharyngeal carcinoma. Arch Otolaryngol Head Neck Surg 2000;126:517-521.

50. Brown PD, Foote RL, McLaughlin MP, et al. A historical prospective cohort study of carotid artery stenosis after radiotherapy for head and neck malignancies. Int J Radiat Oncol Biol Phys 2005;63:1361-1367.

51. Cheng SW, Wu LL, Ting AC, Lau H, Lam LK, Wei WI. Irradiation-induced extracranial carotid stenosis in patients with head and neck malignancies. Am J Surg 1999;178:323328.

52. Dorresteijn LD, Kappelle AC, Scholz NM, et al. Increased carotid wall thickening after radiotherapy on the neck. Eur J Cancer 2005;41:1026-1030.
53. Patel DA, Kochanski J, Suen AW, Fajardo LF, Hancock SL, Knox SJ. Clinical manifestations of noncoronary atherosclerotic vascular disease after moderate dose irradiation. Cancer 2006;106:718-725.

54. Steele SR, Martin MJ, Mullenix PS, Crawford JV, Cuadrado DS, Andersen CA. Focused high-risk population screening for carotid arterial stenosis after radiation therapy for head and neck cancer. Am J Surg 2004;187: 594-598.

55. Narins CR, Illig KA. Patient selection for carotid stenting versus endarterectomy: a systematic review. J Vasc Surg 2006;44:661-672.

56. Meeske KA, Nelson MD, Lavey RS, et al. Premature carotid artery disease in long-term survivors of childhood cancer treated with neck irradiation: a series of 5 cases. J Pediatr Hematol Oncol 2007;29:480-484.

57. Purdy RA, Kirby S. Headaches and brain tumors. Neurol Clin 2004;22:39-53.

58. Bartleson JD, Krecke KN, O’Neill BP, Brown PD. Reversible, strokelike migraine attacks in patients with previous radiation therapy. Neuro Oncol 2003;5:121-127.

59. Partap S, Walker M, Longstreth WT Jr, Spence AM. Prolonged but reversible migraine-like episodes long after cranial irradiation. Neurology 2006;66:1105-1107.

60. Pruitt A, Dalmau J, Detre J, Alavi A, Rosenfeld MR. Episodic neurologic dysfunction with migraine and reversible imaging findings after radiation. Neurology 2006;67:676678. 